\title{
Religion, suffering, and health among older Mexican Americans
}

\author{
Neal Krause ${ }^{a,{ }^{*}}$ and Elena Bastida ${ }^{b}$ \\ aDepartment of Health Behavior and Health Education, School of Public Health, University of \\ Michigan, 1420 Washington Heights, Ann Arbor, MI, 48109-2029, United States \\ benter for Aging and Health, The University of Texas, Pan American, 1201 West University \\ Drive, Edinburg, TX 78539, United States
}

\section{Abstract}

Pain and suffering are deeply embedded in the ethos of Mexican American culture. Consequently, it is not surprising to find that many Mexican Americans turn to their faith in an effort to deal with the pain and suffering that arise in their lives. The purpose of the current study is to explore the interface between pain, suffering, religion, and health among older Mexican Americans. Three major themes emerged from in-depth qualitative interviews with 52 older Mexican Americans. The first is concerned with whether pain and suffering are a necessary part of religious life, the second has to do with the potential benefits that pain and suffering may provide, and the third involves whether it is necessary to bear pain and suffering in silence. In the process of reviewing these themes, an effort is made to show how they may be linked with the physical and mental health of older Mexican Americans.

\begin{abstract}
A vast literature suggests that individuals who are more deeply involved in religion tend to have better physical and mental health than people who are not involved in religion (Koenig, McCullough, \& Larson, 2001). A good deal of this work has been conducted with older adults (e.g., Krause, 2002). This makes sense because research consistently reveals that people who are currently older are more deeply involved in religion than individuals who are presently younger (Barna, 2002). So if religion truly affects health, as many claim, then the impact of religion on health should be especially evident among older adults.
\end{abstract}

As work in this field has evolved, a growing number of researchers have begun to explore the relationship between religion and health in different racial and ethnic groups. So far, virtually all of this research has involved older African Americans (Taylor, Chatters, \& Levin, 2004) while considerably less attention has been given to older adults in other racial groups. This is especially true of older Mexican Americans. This is unfortunate because Hispanic Americans are the most rapidly growing minority group in the country. In fact, demographers predict that older Hispanic Americans will soon pass older African Americans to become the second largest racial group in the United States (Federal Interagency Forum on Aging Related Statistics, 2004). The purpose of the current study is to address this gap in the literature by focusing on how religion may enhance the health and well-being of older Mexican Americans.

Assessing the relationship between religion and health in any racial group is challenging because researchers have known for some time that religion is a complex multidimensional phenomenon (Fetzer Institute/National Institute on Aging Working Group, 1999). As a

(C) 2009 Published by Elsevier Inc.

"Corresponding author. Tel.: +1 734763 5583; fax: +1 734763 7379. nkrause@umich.edu (N. Krause), bastida@utpa.edu (E. Bastida). . 
result, it would be difficult to assess allthe ways in whichreligionmay affect the healthof older Mexican Americans in a single study. Consequently, the goal of the current study is to focus on one aspect of religion that has emerged from our ongoing qualitative work-the interface between religion, pain, and suffering.

Themes of pain and suffering are deeply embedded in many facets of Mexican American life, including religion. There are several historical reasons why pain and suffering occupy such a central role in this culture (Leon, 2004; Rodriguez, 1994). To begin with, the conquest of Mexico by the Spanish led to a three-tiered system of stratification with people born in Spain at the top, people of Spanish decent who were born in the New World in the second tier, and native people and individuals of mixed heritage at the bottom (Rodriguez, 1994). As Leon (2004) points out, those at the bottom encountered a good deal of pain and suffering. In fact, he refers to the period of colonization as the "Mexican diaspora" (Leon, 2004, p. 198).

The deleterious consequences of colonization by the Spanish were exacerbated by a number of subsequent historical events. The Mexican American War of 1848, the Mexican Revolution of 1910, and the labor shortages of World War I each in their own distinct way rekindled the earlier conditions of subordination and diaspora encountered during the Spanish colonization. Although the Mexican origin population in the Southwest at the end of the Mexican American War is estimated at under 100,000 (Gomez, 2007; Nostrand, 1975), the Mexican residents of the newly acquired territories, nevertheless, became "... a dominated people, (who were) rendered politically and economically powerless" (Rodriguez, 1994, p. 68; see also, Gomez, 2007). This led to what Rodriguez (1994) calls the "psychological colonization" of this population. This earlier pattern of domination primed the conditions for the experiences that would be encountered by much larger waves of immigrants following the unrest created by the Mexican Revolution and the labor shortages of World War I. As a result of these later waves of immigration, the U. S. Mexican origin population in 1930 had grown to slightly under 1.5 million (Birdsall \& Florin, 1992; Graton \& Gutmann, 2000). A chapter in Leon's (2004) book, which is titled, "The Terror of Postcolonial History" (p. 23), succinctly captures the impact of these times on the lives of Mexican Americans.

The vestiges of the historical past are evident in the way more contemporary scholars view Mexican culture, and by extension, Mexican American culture. Octavio Paz is a Nobel Laureate who is widely regarded as one of Mexico's leading poets and essayists. In one of his works, The Labyrinth of Solitude, he discusses at length the role that solitude and suffering play in the lives of many Mexicans (Paz, 1985). He defines solitude as “... the feeling and knowledge that one is alone, alienated from the world and oneself ..." (p. 195). He points out that solitude creates a dialectic: " $\ldots$ on the one hand it is self-awareness, on the other it is a longing to escape from ourselves" (p. 195). It is especially important for the purposes of the current study to point out that Paz equates this solitude with suffering: "Popular language reflects this dualism by identifying solitude with suffering ..." (p. 196).

Given the overwhelming impact of historical circumstances and the imprint these broad social forces left on the psyche of people of Mexican decent, it is not surprising to find that many sought comfort in their faith. Perhaps the most visible manifestation of these efforts may be found in the culturally unique beliefs surrounding Our Lady of Guadalupe. Elizondo (1980) provides a detailed account of how the Virgin Mary appeared to Juan Diego, a Mexican peasant, in 1531. The Virgin told Juan Diego that she had come to give faith and courage to the people of Mexico and that she would "... remedy all their miseries, pains, and sufferings" (Elizondo, 1980, p. 31). The apparition of the Virgin in 1531 came at a deeply troubling time in the history of Mexico. As Carrasco (1990) reports, there were close to 25 
million indigenous people living in Mexico in 1500. But due to factors such as disease and slavery, this population was reduced to 1 million by 1600. Mexican American people were drawn to Our Lady because she was seen as belonging specifically to their own culture. In fact, as Fernandez (2007) points out, the Virgin spoke with Juan Diego in Nahuatl, the ancient language of the Aztecs. Moreover, the realization that Our Lady had suffered deeply from the death of her own Son served to strengthen the bond between her and members of the Mexican American community. Over the centuries, Our Lady of Guadalupe “... came to occupy a place so central to Mexican culture that any consideration of the Mexican people in general ... must include reference to her" (Rodriguez, 1994, p. 46).

The historical accounts of pain and suffering are important because they provide valuable insight into the forces that have shaped the religious lives of many older Mexican Americans today. Moreover, as research on Our Lady of Guadalupe reveals, many older Mexican Americans have relied on their faith to help them deal with these challenges. But there is still a lot we do not know about the relationships among religion, pain, suffering, and health in Mexican American culture. In order to move this literature forward, researchers must address two key problems.

First, researchers need to know more about how religion shapes the belief structures that buttress views on pain and suffering among older Mexican Americans. More specifically, greater insight is needed into what older people think religion has to say about why pain and suffering exist, and researchers need to learn more about the social and psychological resources that are provided by religion to help older Mexican Americans deal with these problems in their lives.

Second, researchers need to delve more deeply into the ways in which religious views on pain and suffering may affect the physical and mental health of older Mexican Americans. A substantial amount of research links adversity with physical and mental health (McEwen \& Lasley, 2002), but there do not appear to be any studies that explore the relationships among religion, pain, suffering, and health specifically within this cultural group.

Given these gaps in the knowledge base, it is imperative that researchers turn to older Mexican Americans themselves to find out how issues involving pain, suffering, and religion are experienced in daily life. This is best accomplished by gleaning insights from unstructured interviews with older Mexican American people. This will help ensure that we capture how older Mexican Americans live out the experience of pain and suffering within the context of religion. Moreover, by relying on qualitative techniques, we can convey these experiences through the words and phrases that are used by older Mexican Americans themselves. Other researchers have explored the nature and meaning of pain and suffering in a wider social context (Black \& Rubinstein, 2004), but we have not been able to identify any qualitative studies that focus specifically on older Mexican Americans nor can we find any qualitative studies that examine the role played by religion in this process.

In the discussion that follows, we provide an overview of the mechanics of our qualitative study. Following this, we turn to a detailed discussion of the major themes involving pain, suffering, and religion that emerge from a series of in-depth interviews with a large group of older Mexican Americans. In the process, we search for ways in which the themes that emerge from our data may be linked to physical and mental health in late life. 


\section{Methods}

\section{Study participants}

The older participants in our study were recruited from an ongoing quantitative survey of Mexican Americans who live along the border between Texas and Mexico-the Border Epidemiologic Study of Aging (BESA). The BESA is a longitudinal survey of Mexican Americans aged 45 and older who reside in Hidalgo County and Starr County, Texas. A total of 1132 Mexican Americans have participated in the BESA study. Older Mexican Americans were selected at random for the current study if they met two criteria. First, they had to be at least 65 years of age. Second, when the quantitative study was conducted, study participants were asked if religion was important to them. Older Mexican Americans were included in the current qualitative survey only if they indicated that religion was at least somewhat important to them.

All qualitative interviews took place in the homes of the study participants. The interviews were conducted in 2007. The interviews were conducted in Spanish. All interviewers were bilingual Mexican American women who had considerable experience with in-depth interviewing procedures. The interviews were tape recorded, transcribed, and translated into English. All participants were given a gift card for taking part in the study. The in-depth interviews were designed to probe a number of different facets of religion. For example, questions were asked about the saints, the Virgin of Guadalupe, prayer, forgiveness, and social relationships in the church. Even so, the interviews began with more general questions about the most important part of leading a religious life. Following this, more focused openended questions were asked about a range of topics, including pain and suffering. So, for example, the participants in our study were asked the following question: "Some people have told us that pain and suffering are necessary for spiritual growth and religious development. Would you agree with this?" Then a series of open-ended probes were asked to find out more about reasons for the answers that were given. Following Black and Rubinstein (2004), no attempt was made to define pain or suffering because doing so might artificially constrain the way in which study participants express their views on these issues. A total of 52 in-depth interviews have been conducted so far. However, because we reached the saturation point with questions on pain and suffering, these issues will not be probed further in our ongoing work. Preliminary analysis revealed that the median age for women was 72 and the median age for men is 73 . Moreover, 15 of the study participants were older men and 37 were older women. Forty-two of the older participants in our study said they were Catholics, nine indicated they were members of Protestant denominations, and one reported no religious preference.

\section{Data analysis}

The themes that emerged from the in-depth interviews were identified in a two-level qualitative data inventory. The first level consisted of a more general assessment of the findings. Here, the intent was to sort the data into relatively crude large-level categories (Brenner, Brown, \& Canter, 1985). Following this, second-level codes were extracted that involved more detailed classifications of what respondents had said (Mischler, 1991). Initially, members of the research team reviewed the transcripts of the in-depth interviews on their own. Following this, a series of conversations among the research team members was initiated so that differences in coding schemes could be resolved and a consensus could be obtained on how to best present the data. 


\section{Results}

Three first-level themes emerged from our in-depth interviews that involve beliefs about the necessity of pain and suffering in religious life, the perceived functions of pain and suffering, and whether the faith of older Mexican Americans requires them to bear pain and suffering in silence. These themes, and the second-level themes that emerged within them, are discussed in detail below.

\section{Beliefs about the necessity of pain and suffering}

When people endure very challenging times, they often want to know why pain and suffering have arisen in the first place. As Frankl (1946/1984) so aptly put it, people try to derive a sense of meaning from the events that confront them they want to know if the pain and suffering they experienced are necessary. Consequently, older adults often actively search for explicitly religious reasons for their difficulties. This makes sense because researchers have argued for some time that one of the primary functions of religion is to provide people with a sense of meaning in life (Spilka, Hood, Hunsberger, \& Gorsuch, 2003). The analysis of our in-depth interview data suggests that a number of older Mexican Americans believe that pain and suffering are a necessary part of leading a religious life, but as we shall also show, not all study participants felt the same way.

Pain and suffering are necessary-One 71 year-old Catholic woman believed that suffering was an integral part of life. Moreover, as the following excerpt from the interview with her reveals, she believes it is necessary primarily because God (i.e., Jesus) suffered, as well. "I think we all have to suffer one way or another in life. We all suffer, children, younger people ... it is a suffering that we carry from the moment we are born. We are born suffering. But it must be that we have to go through what God went through...."

Similar views were expressed by a 68 year-old Catholic woman. "It is a way of helping our Lord-in a minimal way- He suffered for us. He suffered and He was a saint. Why shouldn't we suffer when we are sinners?"

Surprisingly, one older study participant indicated that she did not believe that Jesus and Mary ever suffered in the first place. This 68 year-old Catholic woman reported that, "I do not think that they (Jesus and Mary) even suffered because they are saints. They did not feel pain. Some people say they suffered for us, but they did not suffer ... they did not experience pain because they were saints. That's my point of view." At first, this statement may seem unusual because it appears to contradict a good deal of what is reported in the New Testament of the Christian Bible and it is not consistent with the teachings of the Catholic Church (Orsi, 2005). However, this woman's views may point to a deeper and more subtle process in which religious views are influenced by social factors in the wider secular world. Although it is not possible to identify the specific secular forces that shaped this woman's views, they may have arisen from the media, personal experience, or individuals who do not share the same faith. Viewed more broadly, this suggests that the boundaries between the religious and secular worlds are porous, and as a result, religious views are subject to change. This process is sometimes referred to as "syncretism" in the literature (Carrasco, 1990).

But far and away, the majority of the study participants who believe that pain and suffering is a necessary part of religious life felt this way because Jesus suffered when He was crucified. At first, the unquestioning acceptance of suffering, and the almost fatalistic tone that is embedded in this view, may convey a rather passive approach to dealing with difficult times. This is a concern because a vast literature suggests that passive responses to stressors are often associated with undesirable health outcomes (Aldwin, 2007). But deeper reflection 
on these conversations suggests that more than just fatalism may be involved. Instead, as the views of the older Mexican Americans that were presented in this section reveal, they believe they are emulating Jesus and may even be helping Him fulfill His mission on earth by taking on pain and suffering, just as He did.

Pain and suffering are not necessary-Although a number of older Mexican Americans believed that pain and suffering are a key part of leading a religious life, not all agreed. Evidence of this may be found, for example, in the views that were expressed by a 66 year-old man who identified himself as a charismatic. "God loves us. He does not want us to suffer. We are the ones who get off the path, out of the 'good,' and that is when pain and suffering come." So for this study participant, pain and suffering are something that people voluntarily bring upon themselves. Moreover, these difficulties can and should be avoided by living a life that is more in line with religious teachings and principles. But perhaps more important, as his interview reveals, pain and suffering do not have an explicit religious purpose-this is not something that God wants people to endure.

Essentially the same view emerged from an interview with a 74 year-old woman who reported that she was a Jehovah's Witness. She felt that pain and suffering “... is not necessary ..." and that a person "... can be good ... can be obedient ... can be meek without suffering."

Summary-An intriguing pattern begins to emerge when the different views on the necessity of pain and suffering are compared and contrasted. It appears that older Catholics may be especially inclined to believe that pain and suffering are a necessary part of leading a religious life whereas members of other denominations do not necessarily share the same view. There are two reasons why these denominational differences are noteworthy. First, even though the wide majority of older Mexican Americans are Catholic, a growing number are leaving the Catholic Church and are turning to Protestant denominations, especially those that are more conservative or fundamentalist (Espinosa, Elizondo, \& Miranda, 2003). Second, in the process of leaving the Catholic Church, at least some older Mexican Americans appear to be shedding the vestiges of pain and suffering that had been a more integral part of their prior religious life and part of the wider culture in which they are immersed. Viewed more broadly, these findings provide evidence of one way in which religion may help change core cultural characteristics over time. Perhaps this type of reflexive change helps older Mexican Americans develop religious beliefs that are more meaningful and more recognizable to them.

\section{Identifying the functions of pain and suffering in religious life}

If pain and suffering are a necessary part of living a religious life, then older Mexican Americans are likely to believe that bearing these difficulties serves some function. However, the nature of this function is not entirely clear from the data that have been presented so far. Fortunately, the conversations we had with the older Mexican Americans in this study provided valuable insight into this issue. But rather than identifying a single function, the responses of our study participants indicate that pain and suffering may perform a number of different functions in life. As the discussion provided below will reveal, the older Mexican Americans in our study believe that pain and suffering deepen one's faith, make people more sensitive to the plight of others, instill a sense of empowerment in late life, and provide payment or restitution for past sins.

Pain and suffering deepen faith-The participants in our study indicated that there are four main ways in which pain and suffering have deepened their faith: (1) Suffering makes people more aware of their need for God; (2) it helps them better understand the lessons in 
the New Testament; (3) suffering makes people more grateful to God for what He has done for them; and (4) suffering performs a social control function by helping people who have sinned return to the teachings of the church.

When asked if pain and suffering are a necessary part of leading a religious life, one 67 year-old Catholic woman responded by saying, "Yes very. If you have it all, we never need anything, nothing ever hurts, we will never remember there is a God." This observation is consistent with the insights of Charles Horton Cooley, who was one of the founders of modern social psychology. He argued that, "The love of God ... often exists without our being aware of it, until some crisis brings it out" (Cooley, 1927, p. 254). But perhaps more important, the roots of this woman's view may be traced back to her own Spanish heritage. Miguel de Unamuno was one of the leading Spanish essayists and philosophers of the last century. Writing in 1908, he argued that, "Pain discloses God to us and causes us to love Him" (Unamuno, 1908/2007, p. 48).

A 72 year-old Catholic woman reported that her religious views on pain and suffering helped her in a somewhat different way: "I believe that we have to suffer in order to also learn and give more value to His (i.e., Jesus') suffering. Because when I am going through suffering, for example my illness, when they found the tumor in my kidney, all I said was, "God, I give it to you. It was nothing compared to what you suffered." Because of her suffering, this woman felt she was able to grasp the deeper meaning of the crucifixion. And this understanding is important because it helped her cope more effectively with her own problems. In effect, this woman is making what is known in social psychology as a downward social comparison (Gibbons et al., 2002). According to this perspective, people sometimes find it easier to cope with their own problems when they compare their situation with the situation of someone who is faced with even greater difficulty. This allows them to take solace in the fact that even though their own problems may be challenging, things could be worse. The downward social comparison process is important because a well-developed literature links this type of coping response with better physical and mental health (Suls \& Wills, 1991).

Insight into a different way in which suffering may build a deeper faith was provided by a 65 year-old Catholic woman. When asked about stressors in her own life, she replied that, "Many times we may wonder why God punishes us in this way-why is God giving me all these problems? But we also have to think that God suffered more for us than we do for Him. We have to thank Him for what He went through for us rather than questioning why God is allowing things to happen to me." As the views of this woman reveal, the realization that God has suffered for all humanity engenders a deep sense of appreciation and gratitude. This is noteworthy because mounting evidence suggests that feeling grateful to God is associated with better physical and mental health (Emmons \& McCullough, 2004; Krause, 2006a). The health-related benefits of gratitude may arise for a number of reasons. For example, the flood of positive emotions that are associated with feeling grateful are thought to have a direct and beneficial effect on the cardiovascular system because they tend to lower blood pressure as well as heart rates (McCraty \& Childre, 2004). In addition, there is some evidence that older people who feel more grateful to God tend to cope more effectively with the deleterious effects of stressful life events (Krause, 2006a).

Strong undercurrents of the social control function played by religion surfaced in an interview with a 74 year-old woman who reported that she was a member of the Jehovah's Witness faith. She observed that suffering involves pain and sometimes pain helps people adhere more closely to religious teachings and principles: “... when we discipline our children we will spank them and it hurts them ... pain warns us of danger." She went on to say that suffering in this way “... makes a person meek." This suggests that pain and 
suffering performs a social control function-it keeps people in line with official church doctrine. This view is consistent with Durkheim's (1915/1965) discussion of the function of rules in society. And it is also reinforces the perspective found in Ross' (1898) classic paper on the social control function that is performed by religion.

A 91 year-old Pentecostal man pointed to a final way in which suffering may promote a deeper faith. For him, a deeper faith is not something that is merely granted. Instead, it must be earned. "We must suffer because it (has) already been said that if we don't suffer, we don't deserve." As this comment reveals, faith is not something that is given without any effort on the part of the recipient. Faith can only be earned through suffering. Words are not enough, faith must be proven through acts. And some acts are more important than others, especially those that have to do with enduring hard times.

Taken together, the insights that have been provided in this section are consistent with the findings from empirical studies on posttraumatic growth. As Tedeschi and Calhoun (2004) conclude in their review of this literature, "The evidence is overwhelming that individuals facing a wide variety of difficult circumstances experience significant changes in their lives that they view as highly positive" (p. 3). Clearly, as the excerpts from the interviews that were presented in this section reveal, older Mexican Americans who experience pain and suffering find that it has deepened their faith, thereby illustrating one way in which something good may come from something that initially appeared to be bad.

Pain, suffering, and identifying with the plight of others-The views about the function of pain and suffering that have been presented up to this point deal largely with benefits that accrue solely to the individual. However, other study participants helped us see that pain and suffering may perform a wider social function, as well. More specifically, they indicated that pain and suffering help people better understand the suffering that is experienced by others.

Significant insight into this issue was provided by a 77 year-old Catholic woman. She thoughtfully pointed out that, "To believe it, you need to live it. And that is true. Before my children died, when someone died I would tell them, I'm sorry, I know how you feel, and they told me I did not. There is no way you can know until you have been through it. That is, when you know what pain is. Then you can really feel for others, but not until the pain is yours." Mere awareness of the suffering of others is not enough because observing their difficulty from afar fails to convey a full sense of what they are really going through. Instead, as the views of this woman reveal, the only way to fully appreciate the pain of another is to experience it yourself. Doing so should foster compassion and enhance the ability of a fellow sufferer to help another more effectively. The essence of this perspective was captured succinctly by Unamuno (1908/2007), who observed that, "What is charity if not an excess of compassion, a brimming over of it? What is it if not reflected pain that spills over to pity the ills of others and to exercise charity?" (p. 49). Simply put, pain and suffering foster compassion and charity, and compassion and charity build closer social relationships. This is important because a well-developed literature suggests that being embedded in a tightly knit social network has health enhancing effects (Cohen, 2004).

Pain, suffering, and empowerment-Some older study participants told us that reflecting more deeply on the pain and suffering of Jesus and Mary helped them find courage to face the future-it helped them feel they can handle whatever may happen. Evidence of this may be found, for example, in a conversation with a 77 year-old Catholic woman, who put it this way, "Because you concentrate more on pain, you go deeper into your faith, in your life, in your pain and suffering. Faith is a great doctor, a great healer. We need to be aware of that, the fact that if they (Jesus and Mary) suffered, and they could do 
anything, why couldn't we?" As the insights provided by this woman reveal, even though hard times may be unsettling, they provide the motivation for dealing with whatever problems may arise in the future-they foster the drive to overcome any obstacles that may get in the way. The notion that suffering may foster the belief that problems in life can be overcome is important for two reasons. First, an extensive literature suggests that feelings of personal control are associated with better physical health and better mental health in late life (Zaret, Pearlin, and Schaie, 2003). Second, this important control enhancing function may come at a good time because research consistently reveals that feelings of personal control decline precipitously with advancing age (e.g., Mirowsky, 1995).

The redemptive function of pain and suffering-Our in-depth interviews revealed that suffering takes on a redemptive quality for some older Mexican Americans. It is viewed by them as payment for their own misdeeds. And as the excerpts from the interviews that are provided below will reveal, it is better to settle accounts with God in this life than in the next one.

One 77 year-old Catholic woman told us that "Ifeel that if we suffer in this life, we are paying for something we did." The insights provided by a 75 year-old Methodist woman help show why paying for sins in this life is important, "People say it is better, much better, to suffer here than to suffer in the next life. Suffer here and not there. Because if you suffer there, the suffering is eternal ... No, we have to suffer here so that we do not suffer there ... Over there it is forever, there is no way out."

The redemptive function of pain and suffering is important because it represents a way in which a person may feel they have been forgiven by God for the things they have done. Feeling forgiven by God is important because research indicates that people who feel they have been forgiven by God are more likely to forgive others. And people who forgive others tend to experience a heightened sense of psychological well-being (e.g., Krause \& Ellison, 2003).

Summary-The narratives that were reviewed in this section point to a number of major functions that are performed by pain and suffering in late life. When viewed broadly, an overarching theme involving relationships appears to emerge from these interviews. This theme is best illustrated by turning to Davidson's (1972) insightful discussion of the vertical and horizontal dimensions of religion. The vertical dimension refers to the relationship that a person establishes with God whereas the horizontal dimension refers to relationships that an individual develops with other people. Evidence of the vertical dimension abounds in the excerpts provided above. When older Mexican Americans experience pain and suffering, they come to better understand the pain and suffering that was experienced by Jesus.

Because these older Mexican Americans believe they experienced what Jesus went through, this shared experience helps them feel that they have forged a closer bond with Him. But as the interview data further reveal, suffering also enhances the horizontal dimension because it helps people better understand the plight of others. And this serves to forge deeper bonds with them, as well. The essence of this perspective was captured some time ago by the German philosopher Schopenhauer (1851/2004), who argued that “... one might consider that the appropriate form of address between man and man ought to be, not monsieur, sir, but fellow sufferer ... However strange this may sound it corresponds to the nature of the case, makes us see other men in a true light and reminds us of what are the most necessary things; tolerance, patience, forbearance, and charity, which each of us needs and which each of us therefore owes" (p. 50). Strikingly similar views were reached by Unamuno (1913/2006), who observed that, "For we are not merely placed side by side with others in the world, having no common root with them, neither is their lot indifferent to us, but their pain hurts us, their anguish fills us with anguish, and we feel our community of origin and 
suffering even without knowing it" (p. 186). The conclusions involving shared suffering, and the enhanced horizontal relationships that emerge from it, are especially important because a growing literature suggests that older people who build strong ties with others tend to enjoy better health (Krause, 2006b) and they tend to live longer (Krause, 2006c) than older adults who do not form religiously-based relationships with others.

\section{Suffering in silence}

In a fascinating book, Orsi (2005) shows how suffering in silence was a main component of religious education for Catholics in the 1930s through the early 1960s. This time frame is important because many older Catholics came of age during this era. As Orsi (2005) points out, “. .. no matter how severe your suffering ... Jesus' and Mary's were worse, and they never complained" (p. 27, emphasis in the original). But Orsi went on to argue that more than merely suffering in silence is required: "American Catholic religious teachers practiced an especially rough theodicy in which a cheerful, compliant silence was deemed the only appropriate response to human sorrow" (p. 31, emphasis added). As these arguments reveal, suffering in silence is not only required by the church, it must be born with a cheerful demeanor, as well.

Consistent with Orsi's (2005) insights, it was not surprising to find that a number of older Mexican Americans in our study felt that when bad things happen, it is important to suffer in silence. But not everyone felt this way. In the discussion that follows, we explore three main themes that emerged from the in-depth interviews we conducted: (1) the necessity of suffering in silence; (2) the belief that it is not necessary to suffer in silence; and (3) the social and psychological functions of suffering in silence.

Suffering in silence is necessary-When asked if it is important to suffer in silence, an 85 year-old Catholic woman rather bluntly stated that, "Yes (it is important to suffer in silence). Who are you going to complain to? All you can do is keep your mouth shut and pray."

Referring to the Virgin Mary, an older divorced Catholic woman stoically concluded that “... she (i.e., Mary) suffered in silence for her son. We suffer in silence for our children. With this problem I had, I did not even tell my son ... I did not call my sisters ... I faced it alone."

An older Catholic woman felt that suffering in silence is important because ".. only we know what we suffer. That other person will not know. So we swallow what we suffer." Her use of the word "swallow" is intriguing because it suggests that she copes with pain and suffering by suppressing these problems. This is important because a number of studies suggest that problems may fester and get worse when people try to suppress them (Aldwin, 2007).

Most study participants talked about suffering in silence whenever any problem in life is encountered. However, as the interview with this older woman continued, it became apparent that she felt that suffering in silence was appropriate for some, but not all problems. This woman had been abused by her husband. In the process of reflecting on suffering his abuse she wondered, "Well what would I gain by telling anyone those secrets?" This statement, coupled with other issues that emerged during the course of the in-depth interview with her implies that she may suffer in silence when some problems arise, but she may also turn to her social network members when different kinds of difficulties emerge. This, in turn, points to a much deeper and more finely nuanced perspective. The key issue may not be if someone suffers in silence; instead, it may be when or under which circumstances suffering in silence is appropriate. Moreover, this woman's views suggest that 
she practices the official teachings of the church in a more selective manner. If Orsi (2005) is correct, then older people should always suffer in silence. But as the views of this woman reveal, she adheres more closely to official church doctrine in some circumstances than in others.

It is not necessary to suffer in silence-A number of the older Mexican American participants in our study did not feel it is necessary to suffer in silence. Instead, as one 68 year-old Catholic woman put it, "We should not keep our suffering to ourselves. We should talk to each other and ask for help ..."

This view was corroborated by another 60 year-old Catholic woman. When asked if she felt it is important to suffer in silence, she said, "No. Alone you will suffer and suffer." The views of this woman touch on an important point. Suffering in silence may exacerbate or compound problems because those who suffer in silence may not be able to resolve the difficulties that confront them on their own.

If suffering in silence is so deeply ingrained in the Catholic faith, as Orsi (2005) claims, then it should be especially evident among older Catholics with the greatest or deepest faith. However, as the insights provided by a 72 year-old Catholic woman suggest, this may not be true. In the process of discussing the suffering of the Virgin Mary, this woman made the following observation: "But suffering like that, I would not do it in silence. Even at this point where my faith is so much stronger, I still would not suffer in silence."

The excerpts from the conversations that are provided in this section suggest that, for some older Mexican Americans, suffering in silence is not a desirable way to deal with hard times because doing so forgoes the opportunity of benefitting from the help that significant others may provide. This is important because a vast literature reveals that older people who avail themselves of social support during stressful times tend to have better physical and mental health than older adults who remain isolated from others (Krause, 2004). In fact, a number of our older study participants indicated that it is important to reach out to family members and close friends when adversity arises. But as we discuss in the next section, assuming a negative stance with respect to suffering in silence may mask a subtle, but more important set of issues that compel us to assume a more well-rounded perspective on the nature and function of social relationships in late life.

The functions of suffering in silence-A number of older Mexican Americans in our study reported that suffering in silence performed a range of useful functions. One benefitis especially important for older adults. A 72 year-old Catholic woman said that she suffers in silence because she doesn't want to worry her family members: "It benefits me because, for example, I can see it with my son, this one who comes to see me often ... when I'm ill I will not tell him. And he leaves happy. As soon as he leaves, then I can suffer." A similar view was expressed by another older Catholic widow, who indicated that she turned only to God when she suffers because "... I never liked for anyone to see me cry." She went on to point out that this is especially true with respect to how she relates to her daughters. A third Catholic woman, age 65, was even more straightforward about it: AI don't think it's necessary to let people know you are suffering. They would only be burdened unnecessarily. People don't like hearing others complaining, at least I don't. I prefer seeing people happy and content." Taken together, the views expressed by these women suggest that they suffer in silence because they do not want to be a burden to others. This is important because it corroborates for Mexican Americans what gerontologists have been arguing for decades about older people in other populations: That older people value their independence highly and they do not want to be a burden to others, especially family members (Lee, 1985). 
The views expressed by a 91 year-old man point to another function of suffering in silence. He felt that we "... suffer alone ... to become stronger." Rather than relying on others for assistance, this man believed that taking care of things by himself enhanced his own coping abilities and helped him strengthen existing coping skills and acquire new ones. He felt that this would better prepare him for pain and suffering he may encounter in the future.

Much darker motives for suffering in silence emerged from an interview with a 77 year-old Catholic woman. She indicated that suffering in silence is good "... because if you share it with someone they may not understand or mock you because you are suffering. Or they tell you that you deserve it. Then everyone finds out. So it is better to suffer in silence." In essence, this older Mexican American woman is saying that suffering in silence is functional because it helps her avoid criticism (i.e., being mocked) and it ensures that news of her problems will not be spread throughout her social network. These insights are important because they suggest that electing to suffer in silence may not be an entirely individual decision. Instead, the decision to suffer in silence may be shaped, at least in part, by the quality of the interpersonal relationships that are forged by an older person. Because this woman feels that others may mock her and violate her right to privacy, it is clear that she believes that the members of her social network are not supportive and cannot be trusted. Viewed more broadly, the views of this woman suggest that suffering in silence is a social phenomenon that must be viewed within the history of the relationships that are formed with others. If a person has close ties with family members and friends, then suffering in silence may not be the coping response of choice. But if an individual is embedded in a web of conflicted social ties, then suffering in silence may be a pragmatic response to a difficult interpersonal climate. This perspective also provides evidence that the decision to suffer in silence is shaped by more than religious principles alone. Instead, it is also influenced by social relationships outside the church. This provides one way of illustrating how the way people practice religion is a mix of things they have learned at church that are tempered by the experiences and conditions confronting them in the wider secular world.

Many other study participants had more positive motivations for suffering in silence. For some, suffering in silence will invoke the compassion and sympathy of God, and He will comfort and reward those who suffer alone. As one 77 year-old Catholic woman put it, “... one should not be with an aching heart, telling everyone. It is better to be silent, keep things in your heart. Quiet. We have faith that one day God will reward us for all those tears we have shed. So keep that hope that God one day, after all the crying, will dry your tears." This excerpt underscores her belief in a religious payoff for suffering in silence. Some people may suffer in silence because they believe they will be rewarded by God for their troubles.

Summary-The notion of suffering in silence has a long history in the literature. In fact, it can be traced all the way back to the teachings of great Roman stoics, such as Seneca. The work of the stoics is noteworthy because, as Campbell (2004) points out, "Christian writers have not been slow to recognize the remarkably close parallels between isolated sentences in Seneca's writings and verses in the Bible" (p. 18). Writing in the first century A. D., Seneca, who was born in Spain, argued that, "One can do nothing better than endure what cannot be cured and attend accordingly the God at whose instance all things come about. It is a poor soldier that follows his commander grumbling. So let us receive our orders readily and cheerfully, and not desert the ranks along the march-the march of this glorious fabric of creation in which everything we shall suffer is a strand" (Seneca, 2004, p. 199, emphasis added). The similarities between what Seneca wrote and what some of our study participants told us is striking. Moreover, Seneca's (2004) emphasis on suffering with a cheerful demeanor precisely mirrors the teachings of the Catholic Church that were discussed by Orsi (2005). The views expressed by Seneca (2004), the Mexican solitude discussed earlier by Paz (1985), and the tragic sense of life that was elucidated by Unamuno (1908/2007) appear 
to share a common conceptual core. Moreover, the fact that these scholars share a common Spanish heritage helps illuminate the overarching sentiment of the tragic sentiment of life that is woven into Mexican American Catholicism.

\section{Conclusions}

As Black and Rubinstein (2004) convincingly demonstrate, suffering is not a simple unified conceptual phenomenon. Instead, it is a complex multidimensional construct that encompasses a large substantive domain. The purpose of the current study has been to explore the content domain of suffering. But unlike Black and Rubinstein, we were concerned with pain and suffering that arises in a more limited social and psychological context. More specifically, our aim was to explore pain and suffering that is associated with the religious experiences of older Mexican Americans. Viewing pain and suffering in a more limited arena makes it possible to probe more deeply into a number of issues that have not been discussed by other investigators. In the process, our findings help dispel a number of commonly held beliefs about the role that pain and suffering presumably play in the religious lives of older Mexican Americans. Rather than pointing to a tight consensus, the data we provide reveal that some older Mexican Americans feel that pain and suffering are a necessary part of religious life whereas others do not believe this is so. Moreover, for some, suffering is a Biblical necessity that performs a number of important religious functions. But for others, suffering comes only from one's own shortcomings and functions as little more than punishment for sins. Views on how to cope with pain and suffering were also quite varied. For some older Mexican Americans, it is imperative to suffer in silence because they believe that Jesus and Mary suffered in silence. But for other study participants, suffering serves as an occasion to reach out to significant others in order to take advantage of the assistance and advice they can provide. Given the collectivist nature of Mexican American culture (Kaniasty \& Norris, 2000), one might expect to find that all older Mexican Americans would seek support from family members and friends whenever difficult times arise. However, our data suggest this may not be so. This finding provides an interesting example of how some aspects of the Catholic religion may be at odds with elements of the wider racial or ethnic culture in which it is practiced.

Over the course of our in-depth interviews, the older people in our study pointed to a number of ways in which pain and suffering may influence physical and mental health. These linkages are both explicitly religious and decidedly secular. Among the more religious linkages are things like feeling grateful to God. But some of the linkages involving more secular factors were especially thought provoking. This is especially true with respect to the interface between pain, suffering, and social relationships. The potentially important influence of significant others emerges at several key junctures in the process of dealing with pain and suffering. For example, the data we presented suggest that some, but not all, older Mexican Americans choose to suffer in silence while others turn to family members and close friends for help. Our findings further reveal that whether older Mexican Americans avail themselves of this assistance depends, in part, upon the nature of the relationships that have been forged with social network members over time. If relationship histories are rife with conflict, then suffering in silence appears to be a more viable option. Viewed more broadly, the fact that some older Mexican Americans turn to significant others for help provides one way of showing what grand social theorists have been discussing for over a century. More specifically, these grand masters argued that social ties lie at the very heart of religion itself. Evidence of this may be found, for example, in the work of Simmel (1898/1997), who maintained that, "The faith that has come to be regarded as the essence and substance of religion is first of all a relationship between human beings ..." (p. 108, emphasis in the original). 
Although the insights that emerged from our data on pain, suffering, and social relationships are helpful, a number of questions remain unanswered. Four issues that have yet to be explored fully are discussed briefly below.

First, the data indicate that at least some older Mexican Americans turn to their social network members for help when pain and suffering arise. But we know relatively little about what takes place once contact with significant others has been made. Researchers need to find out more about how social network members help define and shape the meaning of pain and suffering, and greater insight is needed into the coping responses they may recommend.

Second, it would be helpful to find out more about the role that a pastor or priest may play when pain and suffering arise. As the official head of a congregation, a priest is often consulted when difficult times are encountered by a rank-and-file church member. In fact, there are a number of journals that deal exclusively with the ways in which members of the clergy assist church members who are confronted by adversity (e.g., Pastoral Counseling). Although there are a number of ways to explore the role that is played by a priest in the pain and suffering process, one of the more intriguing lines of inquiry involves focusing on how assistance from the priest may interface with the informal assistance that is provided by family members, close friends, and fellow church members. Three potentially important scenarios arise in this respect: some older Mexican Americans may rely solely on a priest when pain and suffering is encountered, others may turn only to informal social network members for help, whereas other Mexican Americans may rely on both a priest and informal sources of support. If older Mexican Americans speak only with a priest about pain and suffering, would they still believe they are suffering in silence? If an older Mexican American relies on both a priest and informal network members for assistance, how is the information provided by the priest integrated with the insights provided by informal others to form a more comprehensive response to pain and suffering? For example, it seems as though it would not be difficult for an older Mexican American to know what to do if the advice that is provided by significant others is consistent with, and reinforces, the advice that is provided by a priest. In this instance, evidence of a linking function would be evident between the different elements of an older Mexican American's social world. But the decision about how to cope with pain and suffering may be much more complicated if the advice provided by the two sources is at odds. For example, what happens if a priest advocates the virtues of suffering in silence, but social network members reach out to an older person when they become aware of the plight that confronts him or her? Under these circumstances, would an older person follow the advice of the priest and keep their problems to themselves, or would they instead take advantage of the assistance that is offered by family members and friends? This alternative scenario would depict a substitution function whereby assistance from one source (e.g., a priest) takes precedence over the help that is offered by another source (e.g., family members and friends). As the distinction between the linking and substitution hypotheses reveals, research on pain, suffering, and social relationships provides a rich conceptual context for better understanding the factors that shape the ways in which older Mexican Americans respond to adversity.

The third issue that needs to be explored also involves the issue of suffering in silence. More specifically, research is needed on the factors that promote and reinforce the decision to face adversity alone. The data we provide suggest that this may be a rather complex issue, and the insights that were gleaned from our interviews point to a number of issues that should be explored in this respect. As our data reveal, the decision to suffer in silence may be determined, at least in part, by the nature of the stressor that confronts an older person. Moreover, the decision to face adversity alone may be shaped by relationship histories, as well. Taken together, these insights suggest that the decision to suffer in silence may emerge from a complex matrix of factors involving religious teachings, the nature of the stressor that 
confronts one, and relationships' histories that are formed with informal social network members over time.

The fourth issue involves more delving more deeply into the interface between religion and the wider secular world in which it is embedded. The primary goal of our study was to see how religion shapes the ways in which older Mexican Americans react to the pain and suffering in their lives. However, as our data reveal, the religious views that some older study participants expressed were influenced by the wider secular world-recall the older woman who said that Jesus and Mary never suffered. This suggests that it may not be easy to neatly partition religious and secular life and that more research is needed on the influence that one exerts on the other.

As these unanswered questions reveal, the field of research on religion, pain, and suffering is wide open. This is especially true with respect to research with older Mexican Americans. We hope the work we have done helps other investigators see the value in pursuing research in this field. Doing so should provide valuable insight into one of the key facets of leading a religious life.

\section{Acknowledgments}

This research was supported by grants from the National Institute on Aging: Religion, Aging, and Mexican American Health (R01 AG026259) (Principal Investigator-Neal Krause; Co-Investigator-Elena Bastida) and a grant to Duke University from the John Templeton Foundation (Principal Investigator-Neal Krause).

\section{References}

Aldwin, Carolyn M. Stress, coping, and development: An integrative perspective. Guilford; New York: 2007.

Barna, George. The state of the church 2002. Issachar Resources; Ventura, CA: 2002.

Birdsall, Stephen S.; Florin, John. Regional landscapes of the United States and Canada. Wiley; New York: 1992.

Black, Helen K.; Rubinstein, Robert L. Themes of suffering in late life. Journal of Gerontology: Social Sciences 2004;59B:S17-S24.

Brenner, Michael; Brown, Jennifer; Canter, David. The research interview: Uses and approaches. Academic Press; London: 1985.

Campbell, Robin. Introduction. In: Campbell, R., translator. Seneca: Letters from a Stoic. Penguin Books; New York: 2004. p. 7-29.

Carrasco, David. Religions of Mesoamerica: Cosmovision and ceremonial centers. Waveland Press; Long Grove, IL: 1990.

Cohen, Sheldon. Social relationships and health. American Psychologist 2004;59:676-684. [PubMed: 15554821]

Cooley, Charles H. Life and the student. Alfred A. Knopf; New York: 1927.

Davidson, James D. Patterns of belief at the denominational and congregational levels. Review of Religious Research 1972;13:197-205.

Durkheim, Emile. Elementary forms of religious life. George, Allen, Unwin, Ltd.; London: 1915/1965.

Elizondo, Virgilio. La Morentia: Evangelizer of the Americas. Mexican American Cultural Center; San Antonio, TX: 1980.

Emmons, Robert A.; McCullough, Michael E. The psychology of gratitude. Oxford University Press; New York: 2004.

Espinosa, Gaston; Elizondo, Virgilio; Miranda, Jesse. Hispanic churches in American public life: Summary of findings. Institute for Latino Studies; South, IN: 2003.

Federal Interagency Forum on Age Related Statistics. Older Americans 2004: Key indicators of wellbeing. Washington, DC: U. S. Government Printing Office; 2004. 
Fetzer Institute/National Institute on Aging Working Group. Multidimensional measurement of religiousness and spirituality for use in health research. Fetzer Institute; Kalamazoo, MI: 1999.

Fernandez, Eduardo C. Mexican American catholics. Paulist Press; New York: 2007.

Frankl, Victor. Man's search for meaning. Washington Square Press; New York: 1946/1984.

Gibbons, Frederick X.; Lane, David J.; Gerrard, Meg; Reis-Bergan, Monica; Lautrup, Carrie L.; Pexa, Nancy A., et al. Comparison-level preferences after performance: Is downward comparison theory still useful? Journal of Personality and Social Psychology 2002;83:865-880. [PubMed: 12374441]

Gomez, Laura E. Manifest destinies: The Making of the Mexican American race. New York University Press; New York: 2007.

Graton, Brian; Gutmann, Myron P. Hispanics in the United States, 1850-1990; Estimates of population size and national origin. Historical Methods 2000;33:137-153.

Kaniasty, Krzysztof; Norris, Fran H. Help-seeking comfort and receiving social support: The role of ethnic and context of need. American Journal of Community Psychology 2000;28:545-580. [PubMed: 10965390]

Koenig, Harold G.; McCullough, Michael E.; Larson, David B. Handbook of religion and health. Oxford University Press; New York: 2001.

Krause, Neal. Church-based social support and health in late life: Exploring variations by race. Journal of Gerontology: Social Sciences 2002;44:S332-S347.

Krause, Neal. Stressors in highly valued roles, meaning in life, and the physical health status of older adults. Journal of Gerontology: Social Sciences 2004;59B:S287-S297.

Krause, Neal. Gratitude toward God, stress, and health in late life. Research on Aging 2006a;28:163183.

Krause, Neal. Exploring the stress-buffering effects of church-based social support and secular social support on health in late life. Journal of Gerontology: Social Sciences 2006b;61B:S35-S43.

Krause, Neal. Church-based social support and mortality. Journal of Gerontology: Social Sciences 2006c;61B:S140-S146.

Krause, Neal; Ellison, Christopher G. Forgiveness by God, forgiveness of others, and psychological well-being in late life. Journal for the Scientific Study of Religion 2003;42:77-93. [PubMed: 21373377]

Lee, Gary. Kinship and social support of the elderly: The case of the United States. Ageing and Society 1985;5:19-38.

Leon, Luis. La Llorona's children: Religion, life, and death in the U.S.-Mexican Borderlands. University of California Press; Berkeley, CA: 2004.

McCraty, Rollin; Childre, Doc; Emmons, RA.; McCullough, ME. The psychology of gratitude. Oxford University Press; New York: 2004. The grateful heart: The psychophysiology of appreciation; $p$. 230-255.

McEwen, Bruce; Lasley, Elizabeth Norton. The end of stress as we know it. Joseph Henry Press; Washington, DC: 2002.

Mirowsky, John. Age and sense of control. Social Psychology Quarterly 1995;58:31-43.

Mischler, Elliot G. Research interviewing: Context and narrative. Harvard University Press; Cambridge, MA: 1991.

Nostrand, Richard L. Mexican Americans circa 1850. Annals of the Association of American Geographers 1975;65:378-390.

Orsi, Robert A. Between heaven and earth: The religious worlds people make and the scholars who study them. Princeton University Press; Princeton, NJ: 2005.

Paz, Octavio. The labyrinth of solitude and other writings. Grove Press; New York: 1985.

Rodriguez, Jeanette. Our Lady of Guadalupe: Faith and empowerment among Mexican American women. University of Texas Press; Austin, TX: 1994.

Ross, Edward A. Social Control V. Religion. American Journal of Sociology 1898;2:433-445.

Schopenhauer, Arthur. Essays and aphorisms. Penguin Books; New York: 1851/2004.

Seneca. Seneca: Letters from a stoic. Campbell, R., translator. Penguin Books; New York: 2004. 
Simmel, Georg. A contribution to the sociology of religion. In: Helle, HJ., editor. Essays on religion: Georg Simmel. Yale University Press; New Haven, CT: 1898/1997. p. 101-120.

Spilka, Bernard; Hood, Ralph W.; Hunsberger, Bruce; Gorsuch, Richard. The psychology of religion: An empirical approach. 3rd Edition. Guilford; New York: 2003.

Suls, Jerry; Wills, Thomas A. Social comparison: Contemporary theory and research. Lawrence Erlbaum Associates; Hillsdale, NJ: 1991.

Taylor, Robert J.; Chatters, Linda M.; Levin, Jeffrey. Religion in the lives of African Americans: Social, psychological, and health perspectives. Sage; Thousand Oaks, CA: 2004.

Tedeschi, Richard G.; Calhoun, Lawrence G. Posttraumatic growth: Conceptual foundations and empirical evidence. Psychological Inquiry 2004;15:1-18.

Unamuno, Miguel de. Treatise on love of God. Orringer, NR., editor. University of Illinois Press; Urbana, IL: 1908/2007.

Unamuno, Miguel de. Tragic sense of life. Flitch, JE., editor. Barnes \& Noble; New York: 1913/2006.

Zaret, Stephen H.; Pearlin, Leonard I.; Schaie, K. Warner Personal control in social and life course contexts. Springer; New York: 2003. 